[Jpn. J. Agric. Econ. Vol.19, pp.48-53, 2017]

\title{
Agglomeration Economy and Input-output Linkage: Evidence from the Entry of the Agro-food Industry in China
}

\begin{abstract}
Wenchao $\mathrm{Wu}^{1 *}$
The agro-food industry in China has experienced continuous growth during the last two decades. With booming domestic demand and increasing international trade, numerous firms are expected to be established in the near future. By spatial econometrics model, this research investigates the effect of agglomeration economy and input-output linkage on the setting up of agro-food firms in China. Results suggest that agglomeration economy and input-output linkage strongly predict the entry of firms into the agro-food market. Our finding provides potential insights for the development of rural areas as well as for the location choice of food firms.
\end{abstract}

Key words: agglomeration economy, input-output linkage, Chinese food firms

\section{Introduction}

With its large population, China is the largest producer and consumer of food in the world. The growth of the agro-food industry in China has been impressive, with the annual growth rate in double digits during the past 20 years.

With urbanization and income growth, the processed food market in China is expected to boom drastically. China also plays an important role in international food market, especially in East Asia (Wu and Shuto, 2016).

Also, a large amount of FDI is flowing into the Chinese food market. Food processing companies from Europe and North America, such as Danone, Coca-Cola, Kraft, MasterFoods, Nestlé, PepsiCo, and Tyson, have invested in joint ventures in China and will expand their businesses in the near future (Hawkes, 2008).

In general, agro-food industry in China is quite underdeveloped compared with more developed economies in the world. With booming domestic demand and increasing international trade, a large number of agro-food firms are expected to start up in the near future in China. Then, the question arises as to what factors attract new agro-food firms.

Agglomeration theory suggests that there are great benefits for firms locating together; therefore, new firms are more likely to start up in places where there are already a large number of incumbents from the same industry. From

${ }^{1}$ Graduate School of Life and Environment Science, University of Tsukuba

Corresponding author*: zju.wwc.2008@163.com the perspective of evolutionary economy geography, spin-offs, which are partly separated from existing firms, are the main drive of entrepreneurship. As has been confirmed by Wu et al. (2016), the extent of agglomeration for food industry is high in China. Especially, the extent of agglomeration is higher than that in other countries. Therefore, it would be interesting to know whether agglomeration effects play an important role in the location choice for food firms.

Aside from agglomeration economy, input-output linkage is also important for newly established firms. (Glaeser and Kerr, 2009) found that city demographics, or a culture of entrepreneurship, have very limited roles in explaining the patterns of firm entry across cities in US. Rather, new entrants are particularly drawn to areas that have many small suppliers. The agro-food industry consumes large quantities of the output from such upstreaming industries.

Food sector is a pillow industry for rural areas in China. Attracting food firms is believed to be an effective way to narrow the gap between rural and urban areas. Understanding the location detriments of food industry, especially the effect of agglomeration economy and inputoutput linkage would contribute to making use of their comparative advantage for rural areas. Meanwhile, for food firms, agglomeration economy and input-output linkage are effective ways of cost saving. Thus this research would contribute to the location choice of food firms in China.

In particular, we consider the spatial effect in this research by employing the Spatial Durbin Error Model 
(SDEM) as well as Spatial Durbin Model (SDM) (J. LeSage and Pace, 2009), which allows for spillovers into neighboring observations.

\section{Literature Review and Data}

\section{1) Literature review}

Numerous studies have investigated the location determinants of food-related firms. Henderson and McNamara (1997) found that communities with an established manufacturing base and agglomeration economies are more likely to experience growth. Results from (Henderson and McNamara, 2000) confirm the importance of input-output linkage in the choice of location of food manufactures in the U.S. (Schmit and Hall, 2013) found that both agglomeration economy and market access are important for the growth of the food manufacturing industry in the U.S.

Other factors such as urbanization economies, product markets, available labor force, wage levels, and transportation infrastructure also attract food manufacturing investment (Davis and Schluter, 2005; Lambert and McNamara, 2009; Lambert et al., 2006a; Stewart and Lambert, 2011).

Thus, our hypothesis is that firm entry is more likely to occur in prefectures where a large number of incumbent firms belonging to the same industry exist (agglomeration economy). Also, the existence of upstreaming firms has a positive effect on entry (input-output linkage).

\section{2) Data}

There are mainly two data sources in this research. Number of entry and number of incumbents for each industry are collected from The $1^{\text {st }}$ National Economic Census of China in 2004. It has its advantage compared with survey data commonly used in the literature since in this survey, all enterprises regardless of size are included. The second data source is the China City Statistical Yearbook 2004 from which spatial attributes data are constructed.

In the Chinese Industrial Classification system, there are three two-digit industries belonging to the agro-food industry: $\mathrm{C} 13, \mathrm{C} 14$, and $\mathrm{C} 15$, which correspond to the food processing, food manufacturing, and beverage making industries, respectively. Food processing (C13) firms mainly process raw agricultural products. The outputs of the food processing industry are partly used as input in food manufacturing and beverage making firms. Therefore, input-output linkages exist between the food processing industry and the other two agro-food industries.

In 2004, there were 7017 newly established firms in the food processing industry across the 286 regions, 2845 newly established food manufacturing firms, and 2123 newly established beverage making firms.

\section{Empirical Approach}

\section{1) Empirical model}

Various specifications for spatial econometrics have been developed during the past few decades. Despite the abundant availability in the toolbox, when investigating spillover effects, there are only two model specifications worth considering. (LeSage, 2014b). If the spillover is local, which suggests that the spillover involve only neighbors, Spatial Durbin Error Model (SDEM) is appropriate. In contrast, when the spillover is global, which involve higher-order neighbors, Spatial Durbin Model is usually employed. If there is theoretical background specifically indicating local or global spillover effect, then there is no need to perform specification tests. Since there is no specific theoretical underpinning suggesting the spillover in this research is local or global. We consider SDEM model as our benchmark and conduct SDM as robustness check.

Spatial Durbin Error Model (SDEM) (LeSage and Pace, 2009) allows for local spillovers to neighboring observations through spatial lag terms for the explanatory variables to account for the spatial effect. A similar approach is adopted in the research of LeSage and Ha (2012) to assess the impact of migration on social capital. It takes the form as follows.

$$
\begin{gathered}
y=X \beta_{1}+W X \beta_{2}+u \\
u=\lambda W u+\varepsilon \\
\varepsilon \sim N\left(0, \sigma_{\varepsilon}^{2} I_{N}\right)
\end{gathered}
$$

where $y$ is the number of newly established firms in 2004 in one prefecture and $X$ is the vector of local attributes determining the firms' entry.

The spatial weight matrix $W$ is of dimension $n \times n$, where $n$ is the number of observations. Non-zero elements in row $i$ and column $j$ indicate that region $i$ is a neighbor of region $j$. The main diagonal elements are zero, and rows are normalized so that elements of each row sum to unity. $u$ is the error term. $\lambda$ measures the strength of dependence between units.

Parameters $\lambda, \beta_{1}$ and $\beta_{2}$ are estimated by a maximum likelihood estimation (Bivand and Piras, 2015). In SDEM 
model, $\beta_{1}$ is the direct effect, while $\beta_{2}$ captures the (cumulative) indirect effect (Vega and Elhorst, 2015). By cumulative it means that the coefficient $\beta_{2}$ denotes the sum of spillovers falling on all neighbors (LeSage, 2014).

\section{2) Location determinants}

(1) Agglomeration effects and Input-output linkage Firms locating close to each other benefit from agglomeration from channels of labor market pooling, input sharing and knowledge spillover. Agglomeration factors are assumed to be positively associated with the birth of new firms. In the case of food industry, agglomeration economy has been extensively recorded in the literature (Goetz, 1997; Henderson and McNamara, 1997; Henderson and McNamara, 2000; Cohen and Paul, 2005; Lambert and McNamara, 2009). In this research, number of existing firms belonging to the same industry is used to measure the extent of agglomeration economy. As an example, for food processing industry (C13), number of existing firms in $\mathrm{C} 13$ industry (NO_EX_13) captures the effect of agglomeration economy.

Supplier access is regarded as an important factor predicting the entry of new firms, especially in the perspective of New Economic Geography (Amiti and Smarzynska Javorcik, 2008). Although input market condition is usually included in the analysis of location choice for food firms (Lambert et al., 2006b; Lambert and McNamara, 2009), industrial linkage between agro-food sectors has rarely considered in the literature. Based on IO table and price information, Amiti and Smarzynska Javorcik (2008) construct measure for supplier access and found that access to market and suppliers are the most important factors affecting foreign firm entry in China. For agro-food firms, motivation to be close to supplier would be strong since intensive transport of bulky input and perishable nature of food ingredients. As had been mentioned before, food processing industry (C13) is the upstreaming of food manufacturing (C14) and beverage making industry (C15). Based on these facts, number of existing firms in $\mathrm{C} 13$ industry (NO_EX_C13) is used to measure input-output linkage for $\mathrm{C} 14$ and $\mathrm{C} 15$ industry.

\section{(2) Product market (POP and GDP_Per)}

For food firms, product markets are the source of final demand, therefore approximation to product market is favored as an incentive to minimize distribution costs, as well as save time. Goetz (1997) found that access to markets had a positive effect on food manufacturing location choice in US. Similar facts had been confirmed at county level in US (Henderson and McNamara, 1997; 2000).

Following Lambert and McNamara (2009), population is served as the measure for market size. It is expected that POP will be positively associated with the entry, especially for food manufacturing industry and beverage making industry, whose outputs are consumed as final products. Meanwhile, purchasing power is another aspect that influence demand, so GDP per capital (GDP Per) is also included in the estimation as a measure of market size

\section{(3) Labor cost (WAGE)}

Locations with lower labor costs have lower operating costs, increasing the attractiveness of a prefecture for food firms. It is expected that labor costs will be negatively associated with agro-food firms' entry. Average wage level (WAGE) for in 2004 in each prefecture is used to measure labor cost.

\section{(4) Transport Infrastructure (ROAD)}

Transport infrastructure is the basis to support business activities. Firms locating in areas with well-developed transport network have better access to product and material market, as well as lower transportation costs. Thereby increasing their competitiveness. Thus we use the length of road (ROAD) in one prefecture to measure the influence of transport network on the birth of new firms.

\section{(5) Agriculture output (AGLD)}

Agro-food sector also procures from agriculture sector as inputs. As abundant agricultural products indicates access to raw material for agro-food sector, low price as well as saving of transport cost and time, agriculture output is hypothesized to attract agro-food firms (Lambert and McNamara, 2009). We use land size for agriculture production (AGLD) to proxy the output.

\section{(6) Area of prefecture (AREA)}

In consideration of fact that the size of prefecture may influence the birth of new firms (it is natural to expect more entry in larger prefectures), area of prefecture is included in the regression as a control.

\section{(7) Policy determinants (EcoZone)}

Investment decisions of firms are easily influenced by local policy such as tax holiday. Government of China has established many economic zones to attract investments all over the country. Firms locating in these economic zones could enjoy tax reduction as well as other subsides. In this analysis number of economic zones in each prefecture is 
Table 1. Summary statistics of variables

\begin{tabular}{lllllc}
\hline Label & Mean & S.D. & Min & Max & Units \\
\hline NEW_C13 & 25 & 31 & 0 & 217 & firm \\
NEW_C14 & 10 & 13 & 0 & 84 & firm \\
NEW_C15 & 7 & 8 & 0 & 47 & firm \\
POP & 412 & 289 & 17 & 3144 & person \\
AREA & 16410 & 21875 & 1113 & 253400 & $\mathrm{~km}^{2}$ \\
GDP_Per & 13770 & 11788 & 2126 & 72000 & yuan \\
WAGE & 13710 & 4282 & 6207 & 31930 & yuan \\
AGLD & 329 & 297 & 3 & 2106 & $1000 \mathrm{ha}$ \\
ROAD & 5482 & 3983 & 277 & 34000 & $\mathrm{~km}$ \\
EcoZone & 0.17 & 0.46 & 0 & 4 & zone \\
NO_EX_13 & 218 & 239 & 0 & 1455 & firm \\
NO_EX_14 & 95 & 124 & 0 & 933 & firm \\
NO_EX_15 & 81 & 93 & 0 & 798 & firm \\
\hline
\end{tabular}

Note: Detailed explanations for variable label are in section 3.

used to proxy the policy effect.

Table 1 is the summary statistics of variables, NEW_C13 (NEW_C14, NEW_C15), which is the dependent variable in the estimation, means the number of newly established firms in food processing (food manufacturing, beverage making) industry.

\section{Results and Discussion \\ 1) Benchmark results: SDEM estimation}

Table 2 presents the estimation results of Spatial Durbin Error Model for the three industries. Both Wald test and LR test are significant for three models, justifying the existence of spatial dependence. For the food processing industry (C13), the variable indicating labor cost (WAGE) has a slightly significant negative effect on the entry of new firms, implying that food processing firms are more likely to be located in prefectures where wages are low. The parameter measuring the agglomeration effect (NO_EX_13) is positively significant at the $1 \%$ level, suggesting that food processing firms are attracted to prefectures where there are large numbers of incumbents from the same industry.

Similar to food processing industry (C13), labor cost (WAGE) also negatively affects the entry of firms in food making industry (C14). However in some aspects the results of food manufacturing industry (C14) exhibit features different than the food processing industry. Market access, measured by population (POP) and purchasing power (GDP_Per), positively predicts entry. Notably, this factor was not significant for the food processing industry. The reason behind this is easy to interpret: the output of the food processing industry is mainly for industrial use, while the products of food manufacturing are mostly consumed by consumers. Agglomeration economy (NO_EX_14) is confirmed as a factor in food manufacturing industry (C14).

It indicated that the presence of incumbent firms has a significant effect on the entry of new firms for food manufa-

Table 2. Estimation results of SDEM

\begin{tabular}{|c|c|c|c|}
\hline & $\mathrm{C} 13$ & $\mathrm{C} 14$ & $\mathrm{C} 15$ \\
\hline \multirow[t]{2}{*}{ POP } & 0.00010 & $0.00723^{* *}$ & 0.00237 \\
\hline & $(0.00756)$ & $(0.00283)$ & $(0.00215)$ \\
\hline \multirow{2}{*}{ AREA } & -0.00003 & -0.000003 & -0.00001 \\
\hline & $(0.00005)$ & $(0.00002)$ & $(0.00001)$ \\
\hline \multirow[t]{2}{*}{ WAGE } & $-0.00070^{*}$ & $-0.00030^{*}$ & -0.00008 \\
\hline & $(0.00042)$ & $(0.00016)$ & $(0.00012)$ \\
\hline \multirow[t]{2}{*}{ AGLD } & 0.00542 & 0.00194 & 0.00082 \\
\hline & $(0.00587)$ & $(0.00221)$ & $(0.00168)$ \\
\hline \multirow[t]{2}{*}{ GDP_Per } & 0.00001 & $0.00012^{* *}$ & -0.00001 \\
\hline & $(0.00015)$ & $(0.00005)$ & $(0.00004)$ \\
\hline \multirow[t]{2}{*}{ EcoZone } & -0.33209 & -0.89259 & -0.30420 \\
\hline & $(2.79216)$ & (1.01019) & $(0.76251)$ \\
\hline \multirow[t]{2}{*}{ ROAD } & 0.00039 & 0.00010 & $0.00021^{* *}$ \\
\hline & $(0.00032)$ & $(0.00012)$ & $(0.00009)$ \\
\hline \multirow[t]{2}{*}{ NO_EX_13 } & $0.10347^{* * *}$ & $0.00477^{*}$ & $0.00487^{* *}$ \\
\hline & $(0.00662)$ & $(0.00250)$ & $(0.00189)$ \\
\hline \multirow[t]{2}{*}{ NO_EX_14 } & -0.00403 & $0.06279^{* * *}$ & -0.00287 \\
\hline & $(0.01389)$ & $(0.00518)$ & $(0.00393)$ \\
\hline \multirow[t]{2}{*}{ NO_EX_15 } & 0.00184 & $0.01004^{*}$ & $0.04598^{* * *}$ \\
\hline & $(0.01496)$ & $(0.00557)$ & $(0.00422)$ \\
\hline \multicolumn{4}{|l|}{ Lag } \\
\hline \multirow[t]{2}{*}{ POP } & -0.01218 & -0.00160 & -0.00347 \\
\hline & $(0.01257)$ & $(0.00434)$ & $(0.00327)$ \\
\hline \multirow[t]{2}{*}{ AREA } & -0.00003 & 0.00003 & -0.00002 \\
\hline & $(0.00011)$ & $(0.00004)$ & $(0.00003)$ \\
\hline \multirow[t]{2}{*}{ WAGE } & -0.00025 & 0.00012 & $0.00048^{* *}$ \\
\hline & $(0.00076)$ & $(0.00026)$ & $(0.00020)$ \\
\hline \multirow[t]{2}{*}{ AGLD } & 0.00136 & -0.00243 & 0.00052 \\
\hline & $(0.00871)$ & $(0.00300)$ & $(0.00226)$ \\
\hline \multirow[t]{2}{*}{ GDP_Per } & 0.00023 & 0.00002 & -0.00009 \\
\hline & $(0.00023)$ & $(0.00008)$ & $(0.00006)$ \\
\hline \multirow[t]{2}{*}{ EcoZone } & -1.68390 & -1.61873 & 0.31578 \\
\hline & $(5.49890)$ & (1.98703) & (1.49957) \\
\hline \multirow[t]{2}{*}{ ROAD } & 0.00037 & -0.00011 & -0.00014 \\
\hline & $(0.00066)$ & $(0.00023)$ & $(0.00017)$ \\
\hline \multirow[t]{2}{*}{ NO_EX_13 } & 0.01276 & $0.00787^{*}$ & $0.00589^{*}$ \\
\hline & $(0.01172)$ & $(0.00405)$ & $(0.00304)$ \\
\hline \multirow[t]{2}{*}{ NO_EX_14 } & -0.00271 & 0.00382 & -0.00493 \\
\hline & $(0.02482)$ & $(0.00860)$ & $(0.00646)$ \\
\hline \multirow[t]{2}{*}{ NO_EX_15 } & 0.01526 & -0.00437 & $0.01823^{* *}$ \\
\hline & $(0.02874)$ & $(0.00983)$ & $(0.00738)$ \\
\hline \multirow[t]{2}{*}{ Constant } & 8.17320 & -1.10254 & -3.27455 \\
\hline & $(10.34251)$ & $(3.35353)$ & $(2.50036)$ \\
\hline Observations & 286 & 286 & 286 \\
\hline Log Likelihood & $-1,181$ & -896 & -816 \\
\hline Akaike Inf. Crit. & 2,408 & 1,838 & 1,678 \\
\hline Wald Test $(\mathrm{df}=1)$ & $21.76^{* * *}$ & $6.28^{* *}$ & $4.40^{* *}$ \\
\hline LR Test $(\mathrm{df}=1)$ & $22.10^{* * *}$ & $6.08^{* *}$ & $4.28^{* *}$ \\
\hline
\end{tabular}

Note: 1$)^{*} \mathrm{p}<0.1 ;{ }^{* *} \mathrm{p}<0.05 ;{ }^{* * *} \mathrm{p}<0.01$

2) Numbers in parentheses are standard errors. 
cturing industry. Variable representing input-output linkage (NO_EX_13) is significant for food manufacturing industry, suggesting that the presence of upstream industry (food processing) would promote the entry of firms in downstream industry (food manufacturing). Moreover, significance of NO_EX_13 in lag term proves spillover effects of input-output linkage. It means the presence of upstream industry in one prefecture even encourages the entry of downstream firms in its neighbor prefectures.

Table 3. SDM as Robustness check

\begin{tabular}{|c|c|c|c|}
\hline & $\mathrm{C} 13$ & $\mathrm{C} 14$ & $\mathrm{C} 15$ \\
\hline \multirow[t]{2}{*}{ POP } & 0.00046 & $0.00732^{* *}$ & 0.00237 \\
\hline & $(0.00390)$ & $(0.00286)$ & $(0.00215)$ \\
\hline \multirow[t]{2}{*}{ AREA } & -0.00003 & -0.000004 & -0.00001 \\
\hline & $(0.00005)$ & $(0.00002)$ & $(0.00001)$ \\
\hline \multirow[t]{2}{*}{ WAGE } & -0.00064 & $-0.00030^{*}$ & -0.00011 \\
\hline & $(0.00045)$ & $(0.00015)$ & $(0.00012)$ \\
\hline \multirow[t]{2}{*}{ AGLD } & 0.00555 & 0.00205 & 0.00092 \\
\hline & $(0.00524)$ & $(0.00220)$ & $(0.00163)$ \\
\hline \multirow[t]{2}{*}{ GDP_Per } & -0.00004 & $0.00011 * * *$ & -0.00001 \\
\hline & $(0.00018)$ & $(0.00004)$ & $(0.00004)$ \\
\hline \multirow[t]{2}{*}{ EcoZone } & -0.24076 & -0.84746 & -0.30899 \\
\hline & $(2.61751)$ & $(0.97281)$ & $(0.75776)$ \\
\hline \multirow[t]{2}{*}{ ROAD } & 0.00040 & 0.00011 & $0.00022^{* *}$ \\
\hline & $(0.00039)$ & $(0.00012)$ & $(0.00009)$ \\
\hline \multirow[t]{2}{*}{ NO_EX_13 } & $0.10175^{* * *}$ & 0.00411 & $0.00451^{* *}$ \\
\hline & $(0.00684)$ & $(0.00250)$ & $(0.00193)$ \\
\hline \multirow[t]{2}{*}{ NO_EX_14 } & -0.00410 & $0.06292^{* * *}$ & -0.00248 \\
\hline & $(0.02055)$ & $(0.00522)$ & $(0.00398)$ \\
\hline \multirow[t]{2}{*}{ NO_EX_15 } & 0.00221 & $0.01033^{*}$ & $0.04521^{* * *}$ \\
\hline & $(0.02150)$ & $(0.00557)$ & $(0.00429)$ \\
\hline \multicolumn{4}{|l|}{ Lag } \\
\hline \multirow[t]{2}{*}{ POP } & -0.00992 & -0.00310 & -0.00362 \\
\hline & $(0.01408)$ & $(0.00402)$ & $(0.00304)$ \\
\hline \multirow[t]{2}{*}{ AREA } & -0.00001 & 0.00003 & -0.00002 \\
\hline & $(0.00030)$ & $(0.00004)$ & $(0.00003)$ \\
\hline \multirow[t]{2}{*}{ WAGE } & -0.00008 & 0.00015 & $0.00046^{* *}$ \\
\hline & $(0.00107)$ & $(0.00114)$ & $(0.00019)$ \\
\hline \multirow[t]{2}{*}{ AGLD } & -0.00219 & -0.00256 & 0.00028 \\
\hline & $(0.01320)$ & $(0.00281)$ & $(0.00184)$ \\
\hline \multirow[t]{2}{*}{ GDP_Per } & 0.00028 & 0.000003 & -0.00008 \\
\hline & $(0.00030)$ & $(0.00024)$ & $(0.00006)$ \\
\hline \multirow[t]{2}{*}{ EcoZone } & -2.79163 & -1.46114 & 0.53842 \\
\hline & $(6.88125)$ & (1.91084) & (1.45873) \\
\hline \multirow[t]{2}{*}{ ROAD } & 0.00012 & -0.00012 & -0.00017 \\
\hline & $(0.00111)$ & $(0.00021)$ & $(0.00016)$ \\
\hline \multirow[t]{2}{*}{ NO_EX_13 } & $-0.02601^{*}$ & $0.00675^{*}$ & 0.00452 \\
\hline & $(0.01332)$ & (0.00399) & $(0.00305)$ \\
\hline \multirow[t]{2}{*}{ NO_EX_14 } & 0.00298 & -0.00947 & -0.00381 \\
\hline & $(0.02751)$ & $(0.00942)$ & $(0.00620)$ \\
\hline \multirow[t]{2}{*}{ NO_EX_15 } & 0.01036 & -0.00539 & 0.00691 \\
\hline & $(0.02777)$ & $(0.00816)$ & $(0.00827)$ \\
\hline \multirow[t]{2}{*}{ Constant } & 6.13609 & -0.88451 & -2.85897 \\
\hline & $(10.73305)$ & $(2.29841)$ & $(2.17790)$ \\
\hline Observations & 286 & 286 & 286 \\
\hline Log Likelihood & $-1,180$ & -895 & -815 \\
\hline Akaike Inf. Crit. & 2,406 & 1,837 & 1,676 \\
\hline Wald Test $(\mathrm{df}=1)$ & $26.86^{* * *}$ & $7.40^{* * *}$ & $6.36^{* *}$ \\
\hline LR Test $(\mathrm{df}=1)$ & $23.80^{* * *}$ & $7.01^{* * *}$ & $6.06^{* *}$ \\
\hline
\end{tabular}

Note: 1$)^{*} \mathrm{p}<0.1 ; * * \mathrm{p}<0.05 ; * * * \mathrm{p}<0.01$

2) Numbers in parentheses are standard errors.
Estimates for beverage making (C15) industry highlights the role of transport infrastructure (ROAD). Significance of variables NO_EX_13, NO_EX_15 and their lag terms imply that agglomeration economy and input-output linkage matters as well for this industry.

\section{2) Robustness check: SDM estimation}

In consideration that global spillover effect might exist, we estimate Spatial Durbin Model as the robustness check. In such case, a change of $X$ at any region will be transmitted to all other regions even if two regions, according to $W$, are not adjacent (Vega and Elhorst, 2015). SDM takes the form as follows.

$$
\begin{gathered}
y=\rho W y+X \beta_{1}+W X \beta_{2}+\varepsilon \\
\varepsilon \sim N\left(0, \sigma_{\varepsilon}^{2} I_{N}\right)
\end{gathered}
$$

SDM differs with SDEM in that it has a lag term for dependent variable in the right hand side and the error term structure is not spatially correlated.

Table 3 shows the estimation results of SDM. In general, variables suggesting the importance of agglomeration economy and input-output linkage are still significant, although some variables (NO_EX_13 for C14 industry, lag term of NO_EX_13 and NO_EX_15 for C15 industry) lose their significance. Other variables, reflecting market size (POP and GDP Per), labor cost (WAGE), and transport infrastructure (ROAD) are also very similar to those in SDEM setting.

In summary, main results suggesting the importance of agglomeration effect and input-output linkage are robust under SDM specification.

\section{Conclusion}

Using the Spatial Durbin Error Model, this research investigates the effect of an agglomeration economy and input-output linkages on the setting up of new firms in the Chinese agro-food industry. Results suggest that an agglomeration economy and input-output linkages strongly predict the entry of new firms into an area. The existence of firms from the same industry also has a positive effect on the starting up of firms. As an upstreaming industry, food processing (C13) firms attract the entry of both food manufacturing (C14) and beverage making (C15) industries. Main results are robust under different model specifications.

China is a country with severe rural-urban gap and regional disparity. Narrowing these gaps has always been the central effort for all levels of governments. Food processing firms are often regarded as potential growing 
sources for rural areas (Lambert et al., 2006b). Findings from current investigation suggests new firms are more likely to locate in prefectures where large number of similar firms and suppliers with industrial linkage have already exist. Policies encouraging the clustering of agro-food industry as well as fostering industrial linkage would be an effect way to attract agro-food firms to locate in rural and less developed regions, thus enforcing rural development and regional balance. Jobs brought by the establishment of new firms are also an important source of income for farmer since most employee of agro-food firms comes from part-time farmer.

Echoed with the finding of Cohen and Paul (2009), which revealed significant spillover effect in terms of cost for agro-food firms from proximity to other food manufacturing centers, our findings suggest motivation of agglomeration economy and input-output linkage do exist such that new firms are more likely to born in place where there are already large number of similar and upstream firms, although the detailed mechanism hasn't been analyzed and more like a 'black-box', which require further investigation. Give the potential of food market in China, large number of agro-food firms are expected to be established in the coming future. Our findings provide helpful insight for the location choice of new firms in agro-food sector.

\section{References}

Amiti, M., and Smarzynska Javorcik, B. (2008) Trade costs and location of foreign firms in China. Journal of Development Economics, 85(1-2): 129-149.

Bivand, R., and Piras, G. (2015) Comparing Implementations of Estimation Methods for Spatial Econometrics. Journal of Statistical Software, 63(18) : 1-36.

Cohen, J. P., and Paul, C. J. M. (2009) Spatial and supply/demand agglomeration economies: State- and industry-linkages in the U.S. food system. In G. Arbia and B. H. Baltagi (Eds.), Spatial Econometrics (pp. 263-281).

Davis, D. E., and Schluter, G. E. (2005) Labor-Force Heterogeneity as a Source of Agglomeration Economies in an Empirical Analysis of County-Level Determinants of Food Plant Entry. Journal of Agricultural and Resource Economics, 30(3): 480-501.

Glaeser, E. L., and Kerr, W. R. (2009) Local Industrial Conditions and Entrepreneurship: How Much of the Spatial Distribution Can We Explain? Journal of Economics and Management Strategy, 18(3): 623-663.
Hawkes, C. (2008) Agro-food industry growth and obesity in China: what role for regulating food advertising and promotion and nutrition labelling? Obesity Reviews, 9: 151-161.

Henderson, J. R., and McNamara, K. T. (1997) Community Attributes Influencing Local Food Processing Growth in the U.S. Corn Belt. Canadian Journal of Agricultural Economics 45(3): $235-250$.

Henderson, J. R., and McNamara, K. T. (2000) The Location of Food Manufacturing Plant Investments in Corn Belt Counties. Journal of Agricultural and Resource Economics, 25(2): 680697.

Lambert, D. M., and McNamara, K. T. (2009) Location determinants of food manufacturers in the United States, 20002004: are nonmetropolitan counties competitive? Agricultural Economics, 40(6): 617-630.

Lambert, D. M., McNamara, K. T., and Garrett, M. I. (2006a) An Application of Spatial Poisson Models to Manufacturing Investment Location Analysis. Journal of Agricultural and Applied Economics, 38(1): 105-121.

Lambert, D. M., McNamara, K. T., and Garrett, M. I. (2006b) Food Industry Investment Flows: Implications for Rural Development. The Review of Regional Studies, 36(2): 140-162.

LeSage, J. P. (2014) What Regional Scientists Need to Know about Spatial Econometrics. The Review of Regional Studies, 44(1): 13-32.

LeSage, J., and Pace, R. K. (2009) Introduction to Spatial Econometrics. CRC Press.

LeSage, J. P., and Ha, C. L. (2012) The Impact of Migration on Social Capital: Do Migrants Take Their Bowling Balls with Them? Growth and Change, 43(1): 1-26.

Schmit, T. M., and Hall, J. S. (2013) Implications of Agglomeration Economies and Market Access for Firm Growth in Food Manufacturing. Agribusiness, 29(3): 306-324.

Stewart, L., and Lambert, D. M. (2011) Spatial heterogeneity of factors determining ethanol production site selection in the U.S., 2000-2007. Biomass and Bioenergy, 35(3): 1273-1285.

Vega, S. H., and Elhorst, J. P. (2015) The SLX Model. Journal of Regional Science, 55(3) : 339-363.

Wu, W., and Shuto, H. (2016) Decomposing Intra-Industry and Net One-way Trade of East Asian Food Market. Japanese Journal of Rural Economics, 18: 45-50.

Wu, W., Jin, S., and Tokunaga, S. (2016) Testing Localization of Chinese Food Industries: Evidence from Microgeographic Data. Review of Urban \& Regional Development Studies, forthcoming. 